\title{
0 pensamento ecológico na cobertura jornalística brasileira: o caso da Baía de Guanabara ${ }^{1}$
}

\author{
Ecological thinking in brazilian news coverage: \\ the case of Guanabara Bay
}

\section{Michel Misse Filho}

Mestre em Comunicação e Cultura pela Universidade Federal do Rio de Janeiro (UFRJ), é graduado em Comunicação Social (Jornalismo) pela mesma instituição. Integra o Grupo de Pesquisa Jornalismo Ambiental (CNPq/UFRGS).

E-mail: michelmisse93@gmail.com

\section{Eloisa Beling Loose}

Doutora em Meio Ambiente e Desenvolvimento pela Universidade Federal do Paraná (UFPR), com tese premiada pela Capes, e doutoranda em Comunicação pela Universidade Federal do Rio Grande do Sul (UFRGS). Vice-líder do Grupo de Pesquisa Jornalismo Ambiental (CNPq/UFRGS).

E-mail: eloisa.beling@gmail.com.

\section{RESUMO}

A proposta deste artigo é investigar como as diferentes correntes ou abordagens do pensamento ecológico apresentam-se na cobertura jornalística de $O$ Globo sobre a poluição da Baía de Guanabara, importante elemento ambiental da antiga capital federal, transformada com o avanço da urbanização da Região Metropolitana do Rio de Janeiro. A partir de pesquisa documental e de análise de textos, de viés qualiquantitativo, verifica-se a transmutação da cobertura das questões ambientais da baía na segunda metade do século XX, acompanhando o movimento ambientalista e a própria consolidação do jornalismo ambiental no Brasil. Identificamos a migração de uma cobertura sustentada na beleza natural, típica dos primórdios do jornalismo ambiental, para uma abordagem que considere aspectos mais complexos

10 presente trabalho foi realizado com apoio da Coordenação de Aperfeiçoamento de Pessoal de Nível Superior - Brasil (CAPES) - Código de Financiamento 001. 
relacionados à poluição, alinhada com a transversalidade da pauta e com a reivindicação dos movimentos ambientalistas mais contemporâneos por justiça ambiental.

PALAVRAS-CHAVE: Pensamento ecológico; Cobertura jornalística; Jornalismo ambiental; Baía de Guanabara.

\section{ABSTRACT}

This article seeks to investigate how the different currents or approaches to ecological thinking are presented in $O$ Globo's news of Guanabara Bay's pollution, an important environmental issue of the former federal capital, transformed with the advance of urbanization in the Rio de Janeiro metropolitan area. Employing documentary research and textual analysis with a qualitative and quantitative bias, we conclude that the coverage of the bay's environmental issues was transformed in the second half of the $20^{\text {th }}$ century, following the environmental movement and the consolidation of environmental journalism in Brazil. We identified a shift from a coverage sustained in natural beauty, typical of the beginnings of environmental journalism, to an approach that considers more complex aspects related to pollution, aligned with the transversality of the agenda and with the claim of more contemporary environmental movements for environmental justice.

KEYWORDS: Ecological thinking; News coverage; Environmental journalism; Guanabara Bay

\section{RESUMEN}

Este artículo tiene la intención de investigar cómo se presentan las diferentes corrientes o enfoques del pensamiento ecológico en la cobertura periodística de $O$ Globo de la Bahía de Guanabara, un elemento ambiental importante de la antigua capital federal, transformado con el avance de la urbanización en la región metropolitana de Río de Janeiro. A partir de una investigación documental y el análisis de textos, desde el sesgo cualitativo y cuantitativo, la cobertura de los problemas ambientales de la bahía se transformó en la segunda mitad del siglo XX, luego del movimiento ambiental y la consolidación del periodismo ambiental en Brasil. Identificamos la migración de una cobertura sostenida en belleza natural, típica de los inicios del periodismo ambiental, a un enfoque que considera aspectos más complejos relacionados con la contaminación, alineados con la transversalidad de la agenda y con el reclamo de movimientos ambientales más contemporáneos por justicia ambiental.

PALABRAS CLAVE: Pensamiento ecológico; Cobertura de noticias; Periodismo ambiental; Bahía de Guanabara 


\section{Introdução}

O pensamento ecológico se dissemina e transforma também por conta das práticas jornalísticas, que envolvem escolhas relacionadas aos critérios de noticiabilidade ${ }^{2}$ de cada época e veículo; são eles que permeiam a definição do que é um acontecimento de interesse público, de quem seriam as fontes mais relevantes para serem ouvidas, de como apresentar tais acontecimentos ao público etc. Compreender quais são as perspectivas ecológicas que permeiam o trabalho jornalístico na imprensa brasileira é o objetivo deste texto, que se debruça sobre a cobertura jornalística de $O G l o b o^{3}$, um dos grandes jornais de circulação nacional, sobre a Baía de Guanabara ao longo da metade final do último século.

O caso da Baía de Guanabara nos parece, por uma série de motivos, particularmente emblemático para o jornalismo ambiental brasileiro. Principal símbolo da antiga capital federal e porta de entrada do Brasil para o mundo - além dos portos, os dois principais aeroportos da cidade se localizam em seu interior -, foi também em seu entorno que se constituiu a primeira grande região urbana ${ }^{4}$ e industrial do país, sofrendo com impactos ambientais há décadas. Logo, a pesquisa documental (Gil, 2002) e a análise de conteúdo de textos (Chizzotti, 2014) empreendidas têm como propósito mapear os traços preponderantes do pensamento ecológico e tensioná-los com a própria história do jornalismo ambiental no Brasil. Para isso, pesquisamos as matérias que envolveram a poluição

2 De forma geral, tais critérios são atributos partilhados pela comunidade jornalística que são considerados para que determinado evento ou fato se torne notícia. McQuail (2013) recorda que esses critérios são relativos, pois dependem, dentre outros fatores, do conjunto de acontecimentos disponíveis naquele momento e da capacidade do jornalista cobri-los. Além disso, esses critérios não são imutáveis: "As definições do que é notícia estão inseridas historicamente e a definição de noticiabilidade de um acontecimento ou de um assunto implica um esboço da compreensão contemporânea do significado dos acontecimentos como regras do comportamento humano e institucional" (Traquina, 2005, p.95).

${ }^{3} \mathrm{~A}$ escolha do jornal deu-se pelo acesso e boa instrumentalização de seu acervo digital, bem como por permanecer em circulação ininterrupta até os dias atuais.

${ }^{4} \mathrm{Na}$ virada do século XX, a população carioca era de 811 mil pessoas, quase quatro vezes mais do que São Paulo. Esta só ultrapassaria o Rio no censo de 1960, ambas com mais de três milhões de habitantes e o problema de poluição da baía já sendo noticiado. Disponível em: <https://censo2010.ibge.gov.br/sinopse/index.php?dados=6\&uf=00.> Acesso em: 13/06/2020.

\section{Dossiê O Pensamento Ecológico - https://revistaecopos.eco.ufrj.br/}


da Baía de Guanabara, de 1957 - ano em que foi constatada a primeira ocorrência de utilização do termo "poluição" junto ao termo "Baía de Guanabara" - até 1992, com os preparativos para a realização da Conferência das Nações Unidas sobre o Meio Ambiente e o Desenvolvimento (Eco-92), momento-chave do jornalismo ambiental brasileiro e da própria cobertura da baía.

A primeira parte expõe uma breve revisão de bibliografia sobre o pensamento ecológico ocidental, ponto de partida para compreendermos o contexto brasileiro. Na sequência, apresentamos o surgimento do ambientalismo e os antecedentes do jornalismo ambiental no país, seguido dos resultados oriundos da análise de textos realizada a partir da cobertura da Baía de Guanabara. Por fim, avançamos sobre as reflexões a respeito do jornalismo ambiental e assinalamos a mudança de perspectiva ecológica ocorrida na cobertura jornalística feita n'O Globo: o que antes era posto como uma questão elitizada, de caráter técnico e cientificista, transformou-se em um debate mais plural, com a inclusão de aspectos sociais, políticos e econômicos.

\section{As raízes do pensamento ecológico ocidental: a relação homem-natureza}

Ao tratar dos aspectos que contribuíram para a formação do pensamento ecológico ocidental, não buscamos afirmar origens consensualmente demarcadas como um "início único" de uma onda que desaguaria nos movimentos ambientalistas contemporâneos, mas contextualizar e compreender a importância, para o devido tema, da relação entre sociedade e natureza ao longo dos séculos. Desde que há humanidade, há modificação na natureza, mas as necessidades da humanidade em alterar esse ambiente se amplificaram (Carneiro, 2003). A percepção de que vivemos uma crise ambiental global e/ou uma crise civilizatória, marcada por uma ideia de progresso infinito e sustentada pela hegemonia da racionalidade moderna, faz emergir o pensamento ecológico sob as lentes do Ocidente (Leff, 2016).

Há registros de mudanças no ambiente nas sociedades desde a Antiguidade: o abandono de cidades sumérias pela salinização e pelo alagamento de terras irrigadas, que produziram os primeiros excedentes agrícolas do mundo; o 
desmatamento e erosão do solo nas colinas da Ática, criticados por Platão; o risco de quebras de safras e erosão do solo na Roma antiga, advertido por Columela e Plinio (McCormick, 1992).

No caso dos gregos, a ideia de natureza é expressa pelo termo physis, que pode representar tanto o processo de nascimento e crescimento, quanto a essência própria do ser, sua disposição espontânea, bem como a força originária, criadora do kósmos. Daí ser a physis, por meio dos estudos de cosmologia, a preocupação central dos filósofos pré-socráticos: por exemplo Tales de Mileto, que cogitou a água; Pitágoras, o número; e Heráclito, pelo fogo primordial e a guerra de opostos (Chauí, 1994). A Natureza grega era concebida, ainda, como um processo de eterno surgimento e desvanecimento, ao contrário da cristandade, cuja Natureza tem início e fim, não sendo espontânea, mas criada por um criador externo à própria Natureza (Kesselring, 2000).

Séculos mais tarde, a Idade Moderna aprofundaria a atividade humana sobre a natureza, sobretudo a partir do aumento da experimentação na pesquisa científica e o consequente surgimento das Ciências Naturais. Não cabe aprofundarmos esses termos, mas entende-se que a espécie humana chega ao século XIX envolta na Revolução Industrial, alterando a relação da sociedade com o meio ambiental numa escala nunca vista. Foi a exploração desmedida, motivada pela meta de um crescimento econômico sem limites, que fez emergir de forma ampla um pensamento orientado para o cuidar da natureza. 0 ambientalismo ou ecologismo ${ }^{5}$ se expande como reação a tal contexto (Martínez-Alier, 2007).

Porto-Gonçalves (2005) afirma que a oposição entre homem-sujeito e natureza-objeto ganha mais relevo com a instituição do capitalismo, quando a ciência cartesiana, baseada no dividir para conhecer, e o antropocentrismo, ideia de que o homem é o centro do mundo, adquirem foça para ampliar suas riquezas. Sob esse olhar, o homem se torna possuidor do mundo e a natureza algo externo, a ser dominado. 0 pensamento herdado do Ocidente é calcado na divisão, na fragmentação:

${ }^{5}$ Assim como Martínez-Alier (2007), utilizamos os termos como sinônimos neste texto. 
A disjunção entre a natureza e a sociedade - o real e o simbólico, o corpo e o espírito, a razão e a emoção - deu lugar a uma racionalidade social forjada no esquecimento da natureza e das condições da vida. 0 iluminismo da razão produziu a ideia fantasiosa de um progresso sem limites da Modernidade desconhecendo as leis-limite da natureza nas quais se configura a vida. A crise ambiental é resultante desta construção social. (Leff, 2016, p.140).

Diante da constatação de que a humanidade está destruindo o planeta, eclodem movimentos que postulam a possibilidade de outros modos de vida levando em consideração o meio ambiente - até então tomado somente como recurso. As atenções da sociedade à questão ambiental crescem à sombra do desenvolvimento tecnológico, aliadas também ao progresso da pesquisa científica, ao crescimento populacional e às mudanças nas relações sociais e econômicas. Nesse sentido, apesar de não ser possível delimitar um início oficial do movimento ambientalista, cabe remontarmos a algumas de suas origens no século XIX, em países como a Inglaterra, já em pleno avanço industrial, e os Estados Unidos, emergente economicamente.

O caso britânico deve ser compreendido junto ao avanço científico. 0 crescente interesse pela história natural teve papel fundamental nos estudos da relação do homem com o ambiente, influenciando movimentos pela proteção da vida selvagem. Os desenvolvimentos da botânica, zoologia e das ciências biológicas num geral, estabelecidos por naturalistas desde o renascimento, iam ao encontro também do movimento arcadista setecentista, especialmente em sua exaltação da natureza e seus valores; cabe aí também uma menção à ideia contemporânea do homem natural, não corrompido, do "bom selvagem" de Jean-Jacques Rousseau. E se por um lado o estudo da natureza chegava a representar, à época, também uma forma de estar mais perto de Deus (o Criador de toda a natureza), por outro lado o ideal vitoriano oitocentista dependia da conquista do ambiente externo ao homem pela ciência e tecnologia.

Ao mesmo tempo, também emergia um tipo de "consciência biocêntrica" que aguçava o entendimento da interrelação do homem com a natureza e parte integrante de todas as espécies - reforçada ainda mais com a publicação de $A$ 
origem das espécies, de Charles Darwin —, bem como a responsabilidade moral de proteção da natureza contra abusos. Foi possível, assim, o surgimento de um movimento que advogava contra a crueldade com os animais, provocando naquele momento a instituição de diversas associações de proteção aos animais (McCormick, 1992). Posteriormente, o início do ambientalismo britânico seria ainda reforçado pelo maior interesse em áreas verdes e espaços abertos, como reação às péssimas condições de vida nos centros industriais ingleses.

Já os Estados Unidos, também afetados pela influência do interesse no ambiente natural, tinham a fundamental diferença de que, ao contrário da já explorada Europa, suas virgens terras ainda estavam sendo abertas para a exploração. Ao mesmo tempo, escritores românticos e filósofos americanos foram inspirados pelas belezas naturais, e nomes como Ralph Waldo Emerson e Henry David Thoreau influenciaram fortemente a forma de se pensar a relação com a

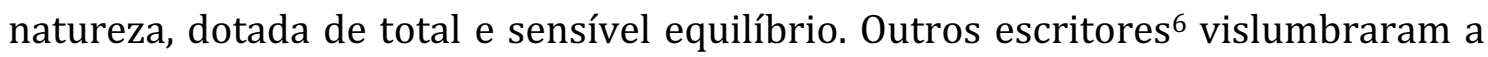
possibilidade de escassez de recursos, seguindo uma linha considerada precursora dos movimentos ambientalistas do século XX. Vale destacar a publicação, em 1864, do livro Man and Nature, de George Perkins Marsh, marco histórico para a formação do ambientalismo. Logo em 1872, os Estados Unidos se tornaram pioneiros com a criação do Parque Nacional de Yellowstone, o primeiro parque nacional do mundo, dando substância ao pensamento de alguns dos escritores citados.

O movimento ambientalista americano não era um corpo uniforme, e já no século XX sucedeu numa ruptura entre preservacionistas e conservacionistas. Os primeiros, representados por John Muir, filosoficamente mais próximos do ponto de vista do protecionismo britânico, eram interessados na preservação de áreas virgens de uso não recreativo ou educacional. Já os conservacionistas, influenciados pelo utilitarismo de Gifford Pinchot, desejavam explorar os recursos naturais de forma racional e sustentável, fundando-se próximos à tradição de uma ciência florestal racional de influência alemã. Estes foram associados ao "progressismo" americano e, entre idas e vindas, penetraram os governos de Theodore Roosevelt e

6 Vale citar nomes como John Ruskin, na Inglaterra, Viollet-le-Duc, na França, e Frederick Law Olmsted, nos EUA (Franco, 2008). 
Franklin Roosevelt. Os anos de 1930 nos Estados Unidos presenciaram, ainda, o chamado Dust Bowl, um dos maiores desastres ambientais da história, quando enormes tempestades de poeira destruíram parte da agricultura americana, como reflexo de décadas de práticas agrícolas inadequadas (McCormick, 1992).

De qualquer forma e a despeito das diferentes vertentes políticas que integravam o incipiente movimento, o que se conhece como "revolução ambiental" — esta, sim, de caráter global - só apareceria com maior intensidade e amplitude no contexto pós-Segunda Guerra Mundial, mais especificamente a partir da década de 1960. Um marco foi a publicação, em 1962, do livro Primavera silenciosa, de Rachel Carson, que tratou o tema dos pesticidas e inseticidas sintéticos, e expôs a necessidade de se cuidar do ecossistema para proteger a saúde humana e o meio ambiente. Num contexto de escalada da corrida nuclear durante a Guerra Fria, a Conferência da Biosfera de 1968 retratou o tema ambiental e precedeu o que seria o maior evento internacional para tratar de meio ambiente até então, tido como divisor de águas do movimento ambientalista: a Conferência de Estocolmo, realizada em 1972 com representantes de 113 países. No mesmo ano foi divulgado, pelo Clube de Roma - grupo formado por cientistas, industriais e políticos - o famoso relatório Os limites do crescimento, alertando para a deterioração do meio ambiente e o esgotamento de recursos não renováveis em função da industrialização acelerada.

No seio da sociedade civil, o que se denominou como "Novo Ambientalismo" era mais dinâmico e com maior base de apoio público, mais centrado na humanidade, com um caráter mais ativista e eminentemente político, antiestablishment e menos filantrópico - ao contrário do velho preservacionismo da luta moral pela preservação da vida selvagem, ou da utilização racional de recursos proposta pelo conservacionismo (McCormick, 1992).

Esse breve histórico alinha-se com as correntes do pensamento ecológico apresentadas por Martínez-Alier (2007): "o culto à vida silvestre", "o evangelho da ecoeficiência" e "o ecologismo dos pobres". Frisa-se que esses movimentos não são homogêneos ou encapsulados, e constituem algumas das principais perspectivas do pensamento ecológico desde seu surgimento até os dias de hoje. 
A primeira corrente defende a ideia de um "preservacionismo puro" da natureza intocada, anterior à presença humana. Em última instância, associa-se à ideia de paraíso perdido, fundamentalmente enraizada na tradição cristã (Diegues, 2008). Conforme Martínez-Alier (2007, p.22), tem como objetivo manter a salvo o que ainda resta da natureza em seu estado original, cercado pela percepção do sagrado, de um "[...] amor às belas paisagens e de valores profundos, jamais para os interesses materiais". Abarca a ideia da sacralidade da natureza e também pode ser associada à perspectiva biocêntrica, convergente com o movimento da "ecologia profunda", que entende que todos os seres estão conectados de forma complexa e interdependente.

A segunda preocupa-se com a questão ambiental e a economia, derivada dos efeitos à saúde e ao ambiente acarretados pelas atividades agrícolas, industriais e de urbanização. O foco é a conciliação de interesses, e há uma crença de que mais ciência e tecnologia podem reverter os problemas ambientais desencadeados pelos processos produtivos (inevitáveis). A natureza é recurso, e o discurso passa a incluir expressões como desenvolvimento sustentável e a economia verde.

A última corrente, ainda segundo Martínez-Alier (2007), volta-se para a (in)justiça ambiental, abarcando os conflitos ecológicos distributivos e as desigualdades sociais. É um movimento entendido enquanto tal a partir de meados dos anos 1980 e que coloca em xeque a exploração não apenas da natureza, mas daquela parcela humana considerada inferior ou com menor valor por quem detém poder.

\section{0 ambientalismo e a formação do jornalismo ambiental brasileiro}

Em um país de história fundamentalmente escravista, com uma economia primária e exploradora de recursos, encontramos uma razoável quantidade de críticas de intelectuais - José Bonifácio, Joaquim Nabuco e André Rebouças, por exemplo -, ainda durante os séculos XVIII e XIX, sobre as questões ambientais pertinentes ao Brasil da época. Ao contrário do viés romântico que caracterizou o início da abordagem ambiental nos países anglo-saxões, a preocupação de 
estudiosos brasileiros, envolta no iluminismo da época, era política, cientificista, pragmática e de defesa do ambiente natural para a construção nacional. É ainda interessante notar a originalidade dos escritos, que abrangiam a importância do tema dentro de uma estrutura maior da sociedade brasileira: Bonifácio, por exemplo, construiu uma relação causal entre o sistema escravocrata e a destruição ambiental, e tratava a temática como forma de superar o passado colonial $-\mathrm{o}$ estrago da natureza brasileira era um custo do atraso, e não do progresso (Pádua, 2002). Já a primeira corrente proposta por Martínez-Alier (2007), do "culto à vida silvestre" chegou a ressoar em alguns momentos no Brasil, mas orientada para determinados biomas, como o Pantanal e a Amazônia, ou áreas específicas, como parques.

Na lacuna compreendida entre os escritos do século XIX e os movimentos ambientalistas modernos do país — desabrochados somente na década de 1970 —, se encontrava o perfil essencialmente conservacionista de grupos como a Sociedade dos Amigos da Árvore, formada por intelectuais, jornalistas e políticos preocupados com o desaparecimento das florestas brasileiras, e que convocou a Primeira Conferência Brasileira de Proteção à Natureza, realizada em 1934, no Rio de Janeiro. Os debates contribuíram para a adoção do Código Florestal de 1934, além de influenciar a criação da legislação para o patrimônio histórico e artístico nacional, que incluía monumentos naturais e paisagens cuja conservação se considerasse interessante (Urban, 2001).

A partir da nova legislação, foi criado o primeiro parque nacional do Brasil na Serra do Itatiaia (1937), seguido pelo Parque Nacional do Iguaçu (1939) e o Parque Nacional da Serra dos Órgãos (1939). Já o Parque Nacional da Tijuca, no Rio de Janeiro, apesar de criado oficialmente apenas em 1961, é considerado pioneiro em termos de proteção e reflorestamento, que datam desde a declaração das florestas da Tijuca e Paineiras enquanto "Florestas Protetoras"7 por D. Pedro II, ainda em 1861 - anterior, portanto, à criação do parque em Yellowstone, nos EUA. Apesar do início de um primeiro movimento conservacionista no Brasil nos anos de 1930,

7 Disponível em: <https://parquenacionaldatijuca.rio/historia-do-parque-nacional-da-tijuca/ >. Acesso em: 11/06/2020. 
apenas os parques de Itatiaia, Iguaçu e Serra dos Órgãos foram criados nesse período, e ainda se estava longe de existir uma política propriamente ambiental no país.

Uma sistematização um pouco maior a favor das demandas ambientais e especialmente do conservacionismo começou a ser desenhada a partir da criação da Fundação Brasileira para Conservação da Natureza (FBCN). Fundada em 1958 no Rio de Janeiro, seus membros formavam um corpo técnico de engenheiros agrônomos e cientistas, imersos na questão ambiental por razões profissionais, com influência sobre o estado em formulação de leis, órgãos e políticas ambientais.

Já no início dos anos 1970, enquanto o mundo ampliava o debate em torno das questões ambientais na Conferência de Estocolmo, o Brasil se encontrava imerso ainda no período de maior repressão da Ditadura Militar, e sob o resultado de décadas de intenso e acelerado crescimento econômico e degradação do meio ambiente. Foi justamente a partir do início do processo de abertura política, por volta de 1974, que tiveram início os primeiros movimentos ativistas ecológicos no país (Viola, 1987). Ao contrário do perfil conservacionista e técnico das décadas anteriores, surgiram grupos ambientais com conotações políticas, incluindo também o espaço urbano na definição do problema ambiental, e promovendo um discurso de crítica à sociedade capitalista e ao estilo de vida moderno: a discussão sobre meio ambiente entrava ainda mais na arena política. A ascensão do socioambientalismo em relação ao conservacionismo (de discurso cientificista e pretensamente apolítico) representaria um tipo de transferência da definição do problema ambiental das ciências naturais para as ciências humanas, incorporando também o humanismo da contracultura, na demanda de uma "ética ecológica" (Alonso, Costa e Maciel, 2007).

Os grupos que surgiram ao longo daquela década confluíam com a redemocratização, dando ainda maior tom político à questão. Alguns exemplos: a pioneira Associação Gaúcha de Proteção ao Ambiente Naural (Agapan), encabeçada por José Lutzenberger, e o Movimento Arte e Pensamento Ecológico (Mape), em São Paulo, formado por artistas, escritores e jornalistas. Juntamente a outros grupos, as coalizões se engajaram no debate contrário ao modelo brasileiro de 
desenvolvimento representado pela ditadura, com protestos como o Movimento em Defesa da Amazônia e a campanha contra a utilização de energia nuclear. Embora fosse um movimento majoritariamente composto por pessoas da classe média, o processo de redemocratização permitiu, além do arrefecimento da repressão, uma conexão maior com outros movimentos sociais populares e com setores da Igreja Católica.

A coalizão de grupos ambientalistas se estruturaria ainda mais no processo de formação da Assembleia Nacional Constituinte, ao consolidar os vínculos e inserir a pauta nos partidos políticos. Poucos anos depois, com a realização da Eco-92, sediada no Rio de Janeiro em 1992, os intensos debates e a introdução de conceitos como o de "desenvolvimento sustentável" pôde abarcar questões de grupos opostos, dando uma tônica comum ao movimento ambientalista brasileiro à época (Alonso, Costa e Maciel, 2007).

Vem da Eco-92, também, a consolidação do jornalismo ambiental como uma especialização temática de um tipo de jornalismo que começara a ser praticado duas décadas antes, e que tem no engajamento e ativismo ecológico uma condição imprescindível para seu surgimento (Belmonte, 2017). Levando-se em conta que a produção jornalística não caminha alheia às demandas sociais de uma época e de um lugar, é plausível perceber as semelhanças entre a trajetória do jornalismo ambiental e a do próprio movimento ambientalista. Embora já fossem publicadas, muitas décadas antes, matérias construídas no ambiente da "natureza", o viés de progresso ou de desbravamento era justamente o oposto do que os movimentos ambientalistas pregavam: recordamos, por exemplo, a famosa reportagem "Enfrentando os Chavantes!", de Jean Manzon e David Nasser para a revista $O$ Cruzeiro em 1944, quando indígenas do Mato Grosso teriam supostamente atacado o avião de onde vieram as fotos que flagravam o momento. Fica cada vez mais claro que a ideia de jornalismo ambiental não se limita a matérias passadas na natureza. O seu caráter transversal, que engloba questões políticas, sociais, econômicas e culturais, ganha força gradualmente a partir dos anos 1970, justamente com a visibilidade dos movimentos ambientalistas no mundo. Contudo, é preciso lembrar, a consolidação dessa especialidade jornalística é lenta e repleta de lacunas, existindo 
momentos de silenciamento e dependendo muito do engajamento individual dos jornalistas.

O começo da cobertura ambiental pelos meios de comunicação na Europa e América do Norte (reproduzido posteriormente em outros países) era centrado em aspectos locais, sendo os problemas do chamado "Terceiro Mundo" ignorados no contexto internacional. As pautas ambientais eram desconectadas de fatores mais amplos, como o desenvolvimento, por exemplo, e voltadas para catástrofes ou acontecimentos perigosos, que, de acordo com Hannigan (1995, P.89), “[...] favorecem enquadramentos monocausais, em vez de enquadramentos que envolvam redes causais longas e complexas".

No Brasil, semelhante ao que ocorreu no mundo, o jornalismo ambiental se origina do jornalismo científico - impulsionado pela atuação da Sociedade Brasileira para o Progresso da Ciência (SBPC) e pela criação da Associação Brasileira de Jornalismo Científico (ABJC) —, e permanece como sua subárea até os preparativos da Eco-92. A emancipação dessa especialização viria apenas com a evolução da mídia ambiental e a transformação de agentes econômicos quanto aos novos tratados internacionais, tecnologias limpas e posturas "ecologicamente corretas", alterando a relação da imprensa especializada com o poder e o público — transformando a mídia ambiental, portanto, em um termômetro para a tomada de decisões (John apud Belmonte, 2017). Esse deslocamento aprofunda as conexões da prática jornalística com o campo ambiental.

Assim, o jornalismo ambiental reconhece os princípios do jornalismo científico, mas ultrapassa-o ao se propor sistêmico e complexo, fundamentado em uma ética e em uma cidadania ambiental, a ponto de sugerir que o ambiental, em sua transversalidade, "contamine", ainda, as demais editorias. (Girardi et al., 2012: 149)

Com a sistematização da área, observa-se que nem todas as matérias que cobrem assuntos ambientais alinham-se com o pensamento ecológico ou com os pressupostos do campo ambiental. A profissionalização da especialidade, por meio de disciplinas nos cursos de Comunicação e Jornalismo, publicações e treinamentos, 
exigiu que o olhar ambiental seja considerado; tal propósito ainda está, contudo, em construção.

Pesquisadores identificam, nas notícias, características como: o olhar fragmentado e distante de uma análise sistêmica e de sua visão interdisciplinar, a despolitização do debate e a espetacularização da tragédia ambiental.

O Jornalismo Ambiental se ressente desta perspectiva acrítica de veículos e jornalistas, que contempla as questões ambientais a partir de fatos isolados, de acidentes ambientais espetaculares, como os tsunamis, os vazamentos de óleo na Baía de Guanabara, matança de indígenas, incêndios incontroláveis de reservas florestais ou aniquilamento em massa da fauna (focas, pinguins, peixes, etc.). Esta síndrome significa uma cobertura estática, paralisante, do meio ambiente, como se fosse possível (e desejável) ver a questão ambiental isolada de sua dinâmica, de suas causas e, portanto, distante dos grandes interesses que a promovem e a sustentam. (Bueno, 2007, p.38).

A apontada cobertura estática do meio ambiente parece ser, sobretudo, uma decorrência da invisibilidade de riscos ambientais para a lógica midiática, somente noticiáveis quando deixam de ser projeções - estado ainda incerto cientificamente e, portanto, menos atrativo jornalisticamente - e transformam-se em acontecimentos reais, em geral, catastróficos (Loose, Camana e Belmonte, 2017).

A crítica de pesquisadores do campo à falta de abordagem sistêmica dos jornais, reduzida a um enfoque puramente noticioso, evidencia a preponderância do destaque ao acontecimento - que pressupõe uma ruptura na "normalidade" —, que é próprio da lógica jornalística. É preciso salientar, todavia, que nem sempre é apenas o acontecimento o gancho que conduz a construção da notícia. Impelido mais pelo desenrolar de um processo que pelo acontecimento, é também comum o movimento de "retroprojeção temporal", evidenciando as causas e consequências de um determinado evento, seus antecedentes e uma maior contextualização, para além da irrupção de algo novo - aliás, seria esse aprofundamento do fato um requisito central para o que se convencionou chamar de "imprensa de qualidade" (Sodré, 2009). 0 jornalismo ambiental contemporâneo defende a ampliação de tal abordagem. Embora menos frequentes, podemos alocar, dentro deste escopo, certos tipos de matérias mais elaboradas e reportagens "especiais" sobre problemas 
ambientais, em que a demonstração das causas e consequências de um processo sistemático e cotidiano de poluição - na Baía de Guanabara, por exemplo — seja mais relevante do que uma possível nova ocorrência que possa configurar novidade.

\section{Confluências entre a Baía de Guanabara e o jornalismo ambiental brasileiro}

Nosso estudo utilizou como procedimento de coleta de dados a pesquisa documental (Gil, 2002), ao identificar materiais que ainda não receberam tratamento analítico, e baseou-se nos passos apresentados por Chizzotti (2014) para a análise de dados, de caráter qualiquantitativo. Assim, os dados analisados foram obtidos de um mapeamento sistemático das matérias d'O Globo que citaram "poluição"8 e "Baía de Guanabara" entre 1957 (a primeira ocorrência) e 1992 (momento-chave do jornalismo ambiental brasileiro e da pauta da baía), e também, sobretudo para fins de contextualização, notícias de outros jornais e referências fora do período citado sobre o objeto de nosso estudo, a Baía de Guanabara. Embora a seleção de matérias sirva ao propósito de traçar paralelos com as correntes de pensamento ecológico (e, para isso, há uma escolha de exemplos representativos), a cobertura jornalística da poluição da baía é abundante e foi permeada por assuntos diversos: apresentação de estudos científicos; promessas de despoluição; denúncias de riscos e crimes ambientais; entrevistas com pescadores e banhistas; problemas no saneamento; ou mesmo citações indiretas, onde a baía não era propriamente o assunto principal da reportagem.

Para análise do material coletado, empregamos livremente as orientações apontadas por Chizzotti (2014) para a análise de conteúdos de um texto, considerando sempre os objetivos do trabalho. Observou-se as recorrências das matérias encontradas (viés quantitativo) e se seus sentidos tinham correspondência com as correntes do pensamento ecológico identificadas na revisão de literatura, que se tornaram nossas categorias analíticas. Ao mesmo tempo, realizamos observações associadas à própria evolução do jornalismo ambiental.

${ }^{8}$ Consideramos o termo estratégico para analisar a cobertura de meio ambiente em um período
extenso, além de abranger as diversas agressões ambientais da baía (esgotos, óleos, resíduos etc.). 
A análise quantitativa realizada mostra que, no total, foram 2162 matérias, distribuídas anualmente no Gráfico 1:

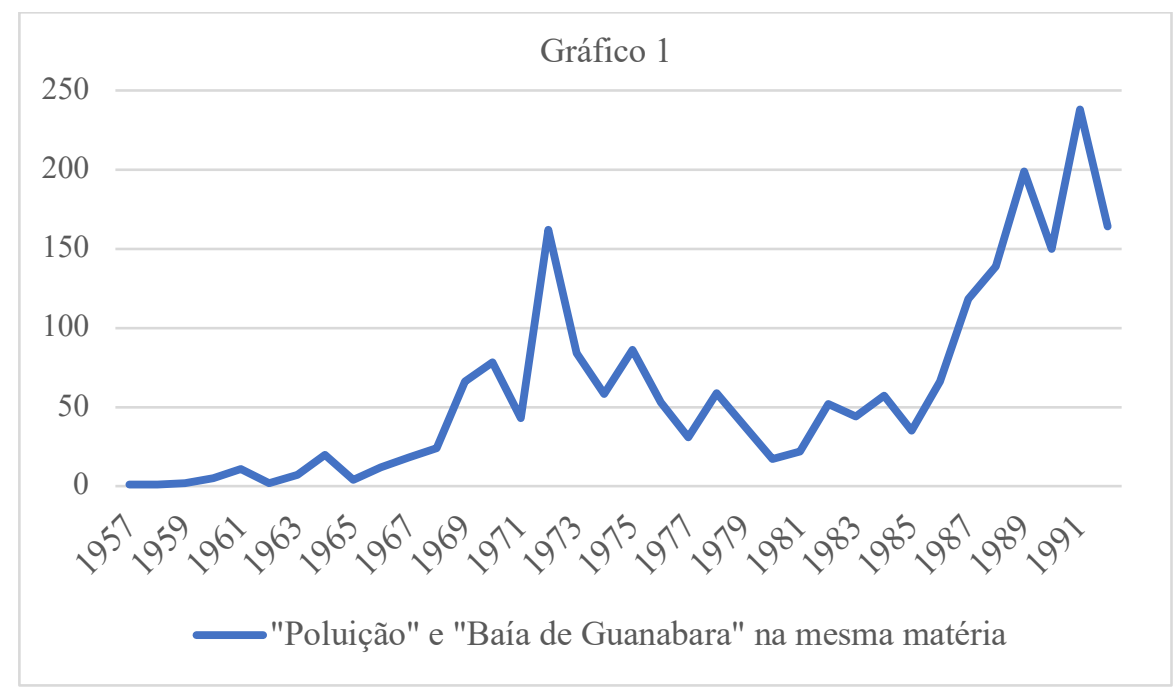

Fonte: Misse Filho (2020).

Os dados revelam que há um pico no começo dos anos 1970, quando a questão da poluição da baía se relaciona com uma doença e uma controvérsia política, seguido de um rebaixamento de atenção, que será retomado, de forma gradual, a partir de 1985, quando o meio ambiente passa a ter uma visibilidade maior - não somente no Brasil - frente às constatações de que há mesmo uma crise ambiental global em curso. Tal linha revela como costuma ser a cobertura jornalística ambiental: esparsa e movida por acontecimentos que não costumam ser acompanhados sistematicamente por jornalistas.

É importante dizer que a não utilização da palavra "poluição" em matérias anteriores a 1957 não significa, contudo, a ausência de referências de cunho ambiental. É o caso de uma matéria de $1927^{9}$, que aponta a devastação vegetal e contaminação local das águas por óleos, e, com o emprego de um tom profundamente romântico e idílico, critica as autoridades brasileiras e sustenta a necessidade preservacionista de manter as belezas naturais, que é convergente com

9 "A impiedade humana devastando a natureza! Árvores que choram e rochas que parecem ter coração - como vão sendo sacrificadas as ilhas da Guanabara” (O Globo, 02/11/1927, p.1). 
a corrente "o culto à vida silvestre", mais representativa no começo do ambientalismo.

As agressões ambientais referentes à Baía de Guanabara não podem ser consideradas um assunto novo, já que datam desde o início da colonização, a partir da extração de pau-brasil, destruição das matas e pesca de baleias. A preocupação ambiental de alguns setores da sociedade brasileira no século XIX chegou a reverberar, já naquela época, na situação da baía. Por exemplo, nos escritos do jornalista Pedro Soares Caldeira, em 1884, que condenam veementemente a destruição dos manguezais da baía e os lodaçais que se alastravam, relacionando-a não só ao desaparecimento e à infecção de peixes e mariscos, mas também aos surtos de febre amarela na cidade - ao contrário da incorreta visão posterior que, ao contrário, associava a doença à presença do mangue (Caldeira, 1884). Aqui é possível identificar uma característica comum à cobertura jornalística de meio ambiente, independentemente do período histórico: as denúncias de crimes ambientais.

É importante frisar que, apesar de evidenciarem uma secular agressão ambiental, tanto os escritos de Caldeira quanto a reportagem de 1927 não tratam exatamente do tipo de poluição que atualmente caracteriza a Baía de Guanabara, ocasionada principalmente pelo despejo de esgotos sem tratamento, além das dezenas de toneladas de lixo, chorume provindo de lixões, vazamentos de óleo e poluição industrial ${ }^{10}$.

Nossa análise qualitativa, embasada na descrição das matérias e articulação com a revisão bibliográfica, busca pontuar os principais momentos em que a cobertura de $O$ Globo manifesta uma viragem na sua abordagem, convergente com as próprias alterações percebidas no movimento ambientalista e no jornalismo ambiental desde 1957, quando a poluição hídrica entendida como generalizada e

${ }^{10}$ A bacia drenante da Baía de Guanabara compreende mais de 8 milhões de pessoas, cuja taxa de tratamento de esgoto, em 2013, ficava em torno de 35\%. Este número foi contestado por especialistas, que chegaram a estimá-lo em 25\%, o que significa o despejo de cerca de 18 mil litros de esgoto in natura por segundo (Alencar, 2016). É improvável que, de 2013 a 2020, esses números tenham se alterado significativamente, sobretudo por conta da crise econômica e da retenção de verbas do Programa de Saneamento Ambiental dos Municípios do Entorno da Baía de Guanabara (PSAM). 
sistêmica — provinda majoritariamente de esgotos domésticos, resíduos industriais e derramamento de óleo - é mencionada, após estudos realizados por cientistas do Instituto Oswaldo Cruz. N’O Globo, foi publicada a matéria “O peixe está desaparecendo: aterros, águas poluídas ou envenenadas contribuirão para que se desertem as águas da Guanabara - um técnico aponta providências imediatas para a solução do problema" (O Globo, 01/08/1957, p.3). Neste momento, é apresentada uma poluição ainda restrita à região em torno da Ilha do Fundão, aterrada entre 1949 e 1952, e que diminuiu drasticamente a circulação das águas, ocasionando o quase desaparecimento da flora e fauna da região.

Esta pioneira matéria foi construída a partir da entrevista com um cientista, o que a concatena com as raízes científicas do jornalismo ambiental. Num primeiro momento, o caráter técnico, cientificista ou provindo de declarações de autoridades públicas esteve presente na maior parte das 169 matérias da década de 1960. Está incluído, neste período, a exposição de fotografias da poluição para o então Presidente da República Jânio Quadros, o que evidenciava a importância daquele tema ambiental já em 1961. Sem grandes reportagens que fossem a campo, trata-se de matérias construídas, em geral, distantes da sociedade, de ordem noticiosa factual e enquadramento técnico do problema.

A mudança de enquadramento deu-se, com contundência, no verão de 1970, após alguns anos de suspeita quanto ao risco de contaminação de hepatite a partir do banho de mar em praias poluídas da baía. Embora haja registros de outros jornais associando, circunstancialmente, o perigo do tifo à poluição de praias cariocas (é o caso de uma matéria do Jornal do Commercio, ainda em 195711), no jornal O Globo a pauta da poluição era ainda dominada pelos problemas relativos à fauna e flora da região. O gancho jornalístico que trataremos vinha de 1968, com uma longa controvérsia na esfera pública, a partir de matérias que ora expunham os perigos da hepatite, ora manifestavam a posição oficial do governo estadual de negar o risco, ao encararem a poluição como um problema de ordem estética.

11 "Praias poluídas põem em perigo toda a população" (Jornal do Commercio, 29/12/1957, p.1). Fonte: Hemeroteca Digital da Biblioteca Nacional. 
Nos dias 7 e 8 janeiro de 1970, todavia, o jornal $O$ Globo publicou duas grandes matérias trazendo, pela primeira vez, dados de laboratórios privados com amostras da água do mar - que comprovavam o perigo - e a opinião de médicos atestando para o surto de hepatite. Mais do que isso, apresentavam uma reportagem mais humanizada, com entrevistas de banhistas e fotografias de crianças se banhando nas águas, em um claro deslocamento do problema de uma poluição restrita à fauna e à flora e que agora atingia a saúde humana (Misse Filho e Paiva, 2020). A mudança de tratamento sobre a baía, em 1970, foi sucedida por um aumento de $309 \%$ nas matérias que pautavam o assunto no referido jornal naquela década, totalizando 692 notícias até 1979, já num patamar de cobertura do assunto similar ao das décadas seguintes.

Essa ruptura de construção das reportagens - que contextualizamos justamente entre a Conferência da Biosfera de 1968 e a Conferência de Estocolmo de 1972 - representa um deslocamento de enquadramento jornalístico similar ao que ocorria no ambientalismo brasileiro, passando de uma posição essencialmente conservacionista, científica e técnica - simbolizada na matéria de 1957 — para o olhar socioambiental dos movimentos que surgiam a partir dos anos de 1970. Notase, do mesmo modo, a forte influência do jornalismo científico sobre as ainda incipientes matérias que tratavam de meio ambiente.

Já ao final daquela década, um maior desenvolvimento do jornalismo ambiental brasileiro pode ser representado pelo primeiro "especial" realizado pelo O Globo sobre o caso da poluição na Baía de Guanabara: "O S.O.S da Baía Agonizante”, que engloba duas grandes reportagens publicadas em 1977. Menos preocupado com um tipo de acontecimento pontual singularizado temporalmente, o olhar jornalístico é, desta vez, atento à construção narrativa da história, personagens, causas e consequências de uma ocorrência, evidenciando traços que se tornariam característicos do jornalismo ambiental contemporâneo.

Na primeira matéria, "Para um problema urgente, uma solução a longo prazo" (O Globo, 07/11/1977, p.37), são entrevistados três pescadores que há décadas atuavam no interior da baía e que relatam o avanço da lama sobre a água, a escassez e gosto de óleo dos pescados e a falta de diálogo com as autoridades. Já a 
segunda reportagem da série, chamada "Um mar de óleo, graxa, esgoto, lixo", aponta para o ano de 2010 em uma projeção para salvar a baía. Traça, ainda, um panorama geral das fontes poluidores da baía, aborda atores técnicos e políticos da época envolvidos no assunto, e trata do planejamento de obras de saneamento.
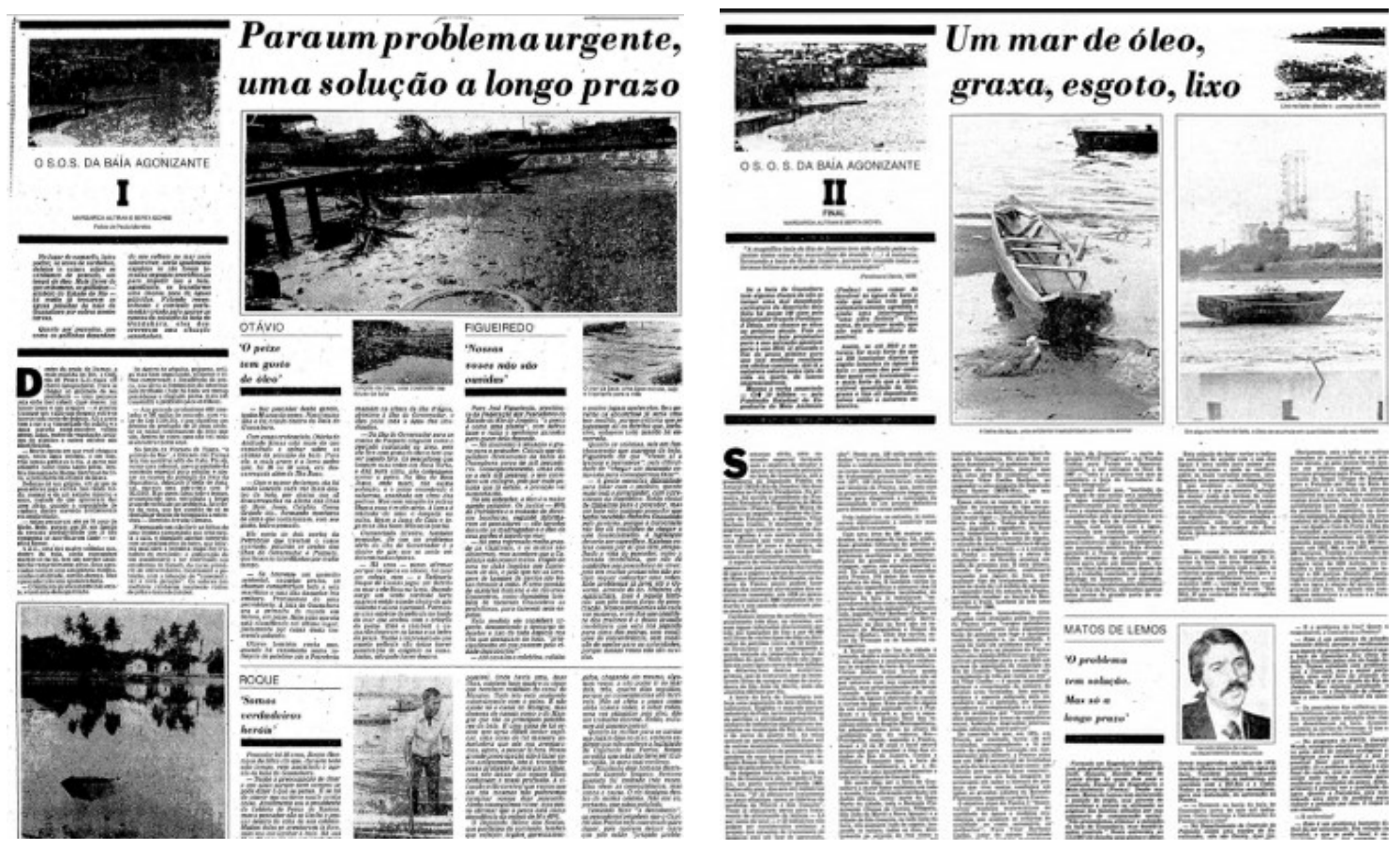

Fonte: Acervo Digital do Jornal O Globo (1977).

É interessante notar que, logo abaixo do título da série, aparece uma citação de 1839 do historiador e viajante francês Ferdinand Denis, fazendo uma ode às belezas naturais da baía. 0 ideal idílico ou romântico — já usado na primeira matéria citada, de 1927- tornou-se uma tendência em grandes reportagens que pode ser vista até os tempos atuais, estabelecendo um contraste entre uma baía de outrora, elogiada pelos antigos viajantes, e a de "agora", acometida pela poluição generalizada. Aludimos à imagem mítica do paraíso perdido e da natureza intocada, que influenciou o preservacionismo norte-americano, e que também é substrato do imaginário social que se formou em torno da Baía de Guanabara.

Além da notada herança romântica que cruza as décadas de cobertura jornalística ambiental, realçamos ainda a representatividade do referido especial 
d'O Globo, para o tema da baía, quanto à primeira fase do jornalismo ambiental no país. Já num contexto de reabertura política, e ao lado de outros grandes temas ambientais da época (por exemplo, as lutas contra a energia nuclear, agrotóxicos e construção da hidrelétrica da Itaipu, além da defesa da Amazônia), a reportagem dá um significativo passo rumo ao desenvolvimento do jornalismo ambiental: desloca a cobertura técnica e distanciada de acontecimentos ambientais e busca, indo a campo, a voz de comunidades tradicionais de pescadores daquele ambiente. Representa, ainda mais, a passagem do antigo conservacionismo para uma abordagem socioambientalista da redemocratização brasileira, endossada pela corrente que trata do ecologismo dos pobres e da justiça social, quando "a própria ideia de meio ambiente é redefinida como relação entre grupos sociais e recursos naturais" (Alonso, Costa e Maciel, 2007, p.157).

Na virada para os anos 1980, a pauta da baía adentra o campo da ação política. Primeiro sob a sombra do Projeto Rio, apresentado pelo governo militar, que previa o aterramento de grande extensão da orla da baía, com o objetivo de acabar com as seis favelas da Maré, manguezais, e pela integração da Ilha do Fundão ao continente. 0 plano foi duramente criticado pelo geólogo e ambientalista Elmo Amador, personagem fundamental da luta pela preservação da baía e defensor incessante da preservação de seu espelho d'água, através da proibição de novos aterros. Após resistência de parte da sociedade, o Projeto Rio não se concretizou da forma como fora concebido, e algumas das propostas de Amador nortearam o debate. Ganhava força a intenção de proteger os manguezais remanescentes do fundo da baía, e em setembro de 1984 foi criada a Área de Proteção Ambiental de Guapi-Mirim, com 14,3 mil hectares, abrangendo os municípios de Magé, Guapimirim, Itaboraí e São Gonçalo, sendo a primeira Unidade de Conservação de Manguezais do Brasil ${ }^{12}$.

Outra demonstração do aprofundamento da relação entre a baía e a política é o desenvolvimento do ativismo ambiental que culminaria na criação do Partido Verde, no Rio de Janeiro, em 1986, com figuras como Carlos Minc, Fernando Gabeira,

12 Disponível em: <http://www.icmbio.gov.br/apaguapimirim/quem-somos/historia.html>. Acesso em: $12 / 06 / 2020$. 
Alfredo Sirkis e Herbert Daniel. Naquele ano, os militantes convocados por Minc lançaram a campanha "SOS Baía", com manifestação na Praia de Botafogo e a ajuda de pesquisadores para diagnosticar os problemas ambientais enfrentados.

Aludimos, ainda, às inúmeras promessas de despoluição noticiadas ao longo das décadas, que podemos associar à corrente da ecoeficiência apontada por Martínez-Alier (2007). Entre esperanças ${ }^{13}$ e desilusões, planos excêntricos ${ }^{14}$ e anúncios de "morte" da baía15, citamos uma grande matéria de 1990, representativa da cobertura ao longo de décadas, intitulada "Mesmo poluída, a Baía sobrevive" $(O$ Globo, 04/02/1990, p.22).

[...] 0 Projeto de Recuperação Gradual dos Ecossistemas não é o primeiro plano de despoluição da Baía da Guanabara. Em janeiro de 1982, o Ministro do Interior, Mário Andreazza, lançou um programa [...] que deveria ser executado em dez anos. [...] Só o tempo dirá se o atual projeto de despoluição não vai se transformar em mais uma daquelas histórias de pescador. [...] As melhorias constatadas pela Feema [...] ainda não foram percebidas pelos pescadores.

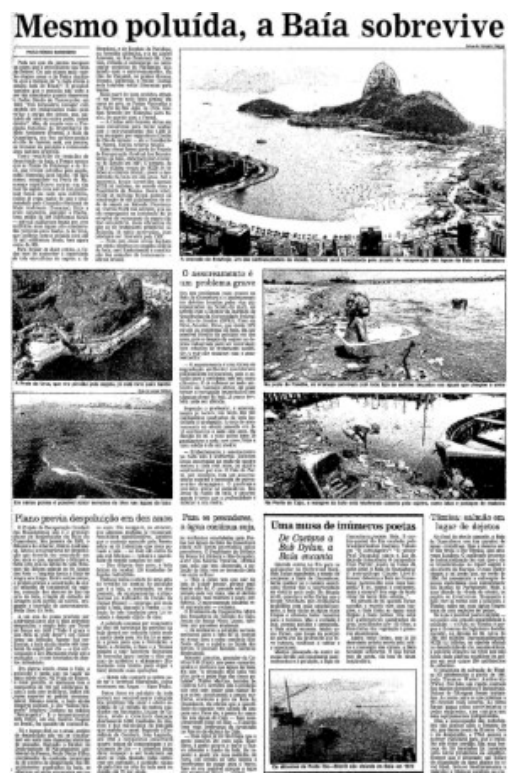

Fonte: Acervo Digital do Jornal O Globo (1990).

13 "Não é quimera, a baía pode voltar a ser pura" (O Globo, 22/10/1973).

14 "Colar flutuante norueguês pode limpar praias do Rio" (O Globo, 22/08/1969); "Tratamento artificial poderá salvar a baía” (O Globo, 02/05/1976).

15 "A morte ronda a fauna e a flora da baía" (O Globo, 08/06/1976); "Guanabara, a lenta morte de uma baía” (O Globo, 06/12/1987). 
A matéria simboliza, ao mesmo tempo, um certo otimismo diante de melhoras pontuais em indicativos ambientais e planos de despoluição, e o olhar desconfiado de promessas outrora não cumpridas, numa tônica que será repetida, casualmente, até os dias atuais. Também cita a recuperação do rio Tâmisa, em Londres, como exemplo a ser seguido - anos depois, outros ambientes seriam, recorrentemente, incorporados ao "painel" de bons exemplos de ecoeficiência: as despoluições das baías de Tóquio, Sidney e Chesapeake.

A essa altura, acontecia o ápice do movimento em prol da baía nos preparativos da Eco-92. A conferência proporcionou a consolidação da pauta entre os mais recorrentes temas ambientais brasileiros - foi esse o período com o maior número de referências à "poluição" e "Baía de Guanabara" na história do jornal $O$ Globo (238 ocorrências em 1991 e 164 no ano seguinte). Ao mesmo tempo, o jornalismo ambiental se consolidava enquanto nicho especializado (Belmonte, 2017) e o movimento ambientalista brasileiro escrevia uma basilar página de sua história. A intrínseca confluência histórica entre este nicho jornalístico e a cobertura da Baía de Guanabara era ainda mais notável naquele momento, e é simbolizada pela transmissão ao vivo do Jornal Nacional, feita pelo repórter Francisco José durante a cobertura da Eco-92, literalmente debaixo do mar na costa fluminense, próximo à entrada da baía. No ímpeto da conferência, foi anunciado, ainda, as bases do que seria o Programa de Despoluição da Baía de Guanabara, iniciado em 1995 e até hoje não finalizado.

\section{Considerações finais}

Ao traçar paralelos entre a cobertura jornalística d'O Globo sobre a Baía de Guanabara e as correntes ou características do pensamento ecológico, buscamos explicitar como a história do ambientalismo se entrelaça com a constituição do jornalismo ambiental. A partir da análise dos textos jornalísticos sobre a Baía no período entre 1957 e 1992, pode-se identificar a passagem de um enquadramento jornalístico mais voltado à corrente "o culto à vida silvestre", na qual o jornalismo

\section{Dossiê O Pensamento Ecológico - https://revistaecopos.eco.ufrj.br/}


se limita a pautas de fauna e flora com enquadramentos mais românticos/idílicos, para outros enquadramentos concordantes com a perspectiva da ecoeficiência, associada ao credo científico e tecnológico, e com aquela relacionada à luta pelas injustiças sociais, denominada "ecologismo dos pobres". Apesar de não existir uma evolução cronológica no pensamento ecológico e das correntes propostas por Martínez-Alier (2007), existindo inclusive inúmeros atravessamentos das diferentes abordagens em todas as épocas, nota-se que a complexidade e transversalidade do campo ambiental se espraia nas práticas jornalísticas dedicadas ao tema, sendo cada vez mais raro tratar de pautas de fauna e flora apenas sob a ótica preservacionista ou dos encantos da natureza.

Verificamos, com a investigação do caso da Baía de Guanabara, um fato bruto já notório e antigo - o lançamento de esgotos sem tratamento na água - ser traduzido na categoria de "poluição" e realocado ao lugar de um problema público, que percorrerá o noticiário da década de 1950 em diante nas páginas de $O$ Globo. A análise da forma com que se percorre a história da cobertura da baía - das características técnicas e científicas das primeiras matérias à "humanização" do problema, passando por sua politização e pela cobertura de grandes tragédias permite direta associação com a história do ambientalismo e do jornalismo brasileiro, de forma específica, e com aspectos do pensamento ecológico ocidental, sob um olhar mais abrangente.

O começo do movimento ambientalista brasileiro impulsiona a cobertura jornalística, trazendo demandas locais, mas que aos poucos se expandem para a escala global. Não apenas cientistas são consultados para a elaboração das notícias. O que antes era visto como um problema que só preocupava uma elite torna-se um debate amplo, que não mais dissocia as escolhas políticas e econômicas dos efeitos negativos que acometem o lugar onde vivemos. Os enquadramentos monocausais cada dia mais perdem o sentido. 0 jornalismo ambiental, a nosso ver em processo de consolidação, se profissionaliza e mobiliza novos ângulos e conexões. Procura instigar uma visão interdisciplinar, plural e coincidente com os anseios de uma pauta focada em processos, com causas e consequências, e não unicamente no registro instantâneo do acontecimento. 
Se o jornalismo está inserido nas questões socioculturais de um tempo, devese compreender que também é influenciador deste, como participante ativo de uma época. Buscar as histórias de cobertura jornalística da Baía é refletir sobre a história dessa luta ambiental, e abre a possibilidade de desenvolvimento de diferentes olhares para abarcar o tema. A Baía de Guanabara - que já foi estudada em termos geológicos, sanitários, químicos, oceanográficos etc. - deve também ser abordada sob um olhar comunicacional e, especificamente, sob as lentes do jornalismo. Afinal, os meios de comunicação são em boa parte responsáveis pelos imaginários e pelas construções sociais que temos da natureza e de nossa relação com ela.

\section{Referências bibliográficas}

ALENCAR, Emanuel. Baía de Guanabara: descaso e resistência. Rio de Janeiro: Fundação Heinrich Boll / Mórula, 2016.

ALONSO, Angela.; COSTA, Valeriano; MACIEL, Débora. Identidade e estratégia na formação do movimento ambientalista brasileiro. In: Novos Estudos, n.78, p.151-167. São Paulo, 2007.

BELMONTE, Roberto Villar. Uma breve história do jornalismo ambiental brasileiro. In: Revista Brasileira de História da Mídia, vol.6, n.2, p. 110-125. Porto Alegre, 2017.

BUENO, Wilson. Jornalismo ambiental: explorando além do conceito. In: Desenvolvimento $e$ Meio Ambiente, n.15, p. 33-44. Curitiba: Editora UFPR, 2007.

CALDEIRA, Pedro Soares. $O$ corte do mangue: sobre o antigo e atual estado da Baía do Rio de Janeiro. Rio de Janeiro: Typographia Imp e Const. J. Villeneuve, 1884.

CARNEIRO, Augusto C. A História do Ambientalismo - O Socialismo, a Direita e o Ecologismo. Porto Alegre: Editora Asgra Luzzato, 2003.

CHAUÍ, Marilena. Introdução à história da filosofia: dos pré-socráticos a Aristóteles. São Paulo: Brasiliense, 1994.

CHIZZOTTI, Antonio. Pesquisa qualitativa em ciências humanas e sociais. Petrópolis: Vozes, 2014.

DIEGUES, Antonio Carlos Sant'Ana. O mito moderno da natureza intocada. São Paulo: Hucitec, 2008.

FRANCO, Maria. Planejamento Ambiental para a cidade sustentável. São Paulo: Annablume, 2008. 
GIL, Antonio Carlos. Como elaborar projetos de pesquisa. 4aㅡ ed. São Paulo: Editora Atlas, 2002.

GIRARDI, Ilza et al. Caminhos e descaminhos do jornalismo ambiental. In: $C \& S$, v.34, n.1, p. 131-152. São Bernardo do Campo, 2012.

HANNIGAN, John A. Sociologia Ambiental - A formação de uma perspectiva social. Lisboa: Instituto Piaget, 1995.

KESSELRING, Thomas. O conceito de natureza na história do pensamento ocidental. In: Episteme, n.11, p. 153-172. Porto Alegre, 2000.

LEFF, Enrique. A aposta pela vida - Imaginação sociológica e imaginários sociais nos territórios ambientais do Sul. Petrópolis-RJ: Vozes, 2016.

LOOSE, Eloisa Beling; CAMANA, Ângela; BELMONTE, Roberto Villar. A (não) cobertura dos riscos ambientais: debate sobre silenciamentos do jornalismo. In: Revista FAMECOS, v.24, n.3, ID26545. Porto Alegre, 2017.

MARTÍNEZ-ALIER, Joan. O ecologismo dos pobres. São Paulo: Contexto, 2007.

McCORMICK, John. Rumo ao paraíso: a história dos movimentos ambientalistas. Rio de Janeiro: Relume-Durnarã, 1992.

McQUAIL, Denis. Teorias da Comunicação de Massa. Porto Alegre: Penso, 2013.

MISSE FILHO, Michel \& PAIVA, Raquel. A poluição na Baía de Guanabara e a emergência da pauta ambiental no jornal O Globo. In: RECIIS - Revista Eletrônica de Comunicação, Informação \& Inovação em Saúde, v.15, n.2, p. 292-306. Rio de Janeiro, 2020.

PÁDUA, José Augusto. Um sopro de destruição: pensamento política e crítica ambiental no Brasil escravista, 1786 - 1888. Rio de Janeiro: Zahar, 2002

PORTO-GONÇALVES, Carlos Walter. Os (des)caminhos do meio ambiente. 12ª ed. São Paulo: Contexto, 2005.

SODRÉ, Muniz. A narração do fato: notas para uma teoria do acontecimento. Petrópolis, RJ: Vozes, 2009.

TRAQUINA, Nelson. Teorias do Jornalismo Volume II - A tribo jornalística: uma comunidade interpretativa transnacional. Florianópolis: Insular, 2005.

URBAN, Teresa. Missão (quase) impossível: aventuras e desventuras do movimento ambientalista no Brasil. São Paulo: Peirópolis, 2001.

VIOLA, Eduardo. O movimento ecológico no Brasil (1974 - 1986): do ambientalismo à ecopolítica. In: Revista Brasileira de Ciências Sociais (RBCS), v.1, n.3. p. 5-26. São Paulo, 1986. 